\title{
The statues of 'Ain Ghazal: discovery, recovery and reconstruction Kathryn W. Tubb
}

The early Neolithic site of 'Ain Ghazal in Jordan is famous for the discovery there of a cache of 28 lime-plaster statues that are among the earliest known large-scale human figures, dated to approximately 8700 years ago. ${ }^{1}$ The member of the Institute's staff who is responsible for the conservation of the statues describes how she set about recovering, investigating and reconstructing them.

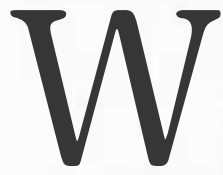

ould it be stretching the reader's imagination too far if I were to begin this article with the fairy-tale phrase "Once upon a time Such an opening may conjure up a tale of the supernatural, of mythical figures in a past so remote as to be largely incomprehensible, and yet it might not be an inappropriate way to introduce the immensely old statues that are the subject of this article (Fig. 1). These mysterious human figures usually evoke, in those who see them today, a sense of power, a power not altogether benign, a power sometimes tinged with dread. So the fairy-tale beginning may not be altogether inappropriate. Alternatively, it would certainly be true just to begin with the phrase "Little did I know.

Discovery and rescue of the statues In the 1970 s a previously unknown Neolithic site was discovered on the outskirts of Amman during the construction of a motorway. In the course of making an access terrace to take bulldozer traffic, a long section was cut mechanically along a slope, and red-plaster floors, typical of the Pre-Pottery Neolithic B (PPNB) period in the seventh millennium BC, were revealed. Mohammed Maraqten, a Jordanian archaeologist who was keeping a watching brief on material exposed by the construction work, notified the Jordanian Department of Antiquities of the discovery. In the early 1980 s the site, which had been under olive cultivation for many years, was threatened by further development as Amman expanded. It was therefore decided that a rescue excavation should be undertaken to assess the nature of the remains.

An initial field season in 1982, under the auspices of Yarmouk University and the Jordanian Department of Antiquities, showed that further investigation was fully warranted. ${ }^{2}$ The site offered a great archaeological opportunity because the evidence of Neolithic occupation lay close to the present surface. It is unusual to find such early settlements without a 30-40 m overburden of subsequent occupation layers overlying them. For example, at the famous site of Jericho, the areas of early Neolithic occupation exposed during excavations by the British archaeologists
John Garstang in the 1930s and Kathleen Kenyon in the 1950s were, for this reason, very limited.

During a second field season in 1983, while excavating in PPNB levels, the astonishing discovery was made as human figures began to be uncovered (Fig. 2). Diana Kirkbride, the British archaeologist who excavated the Neolithic sites of Beidha in
Jordan and Umm Dabaghiya in Iraq, was visiting 'Ain Ghazal at the time and told me later that she had immediately associated the find with similar figures recovered by Garstang in 1935 at Jericho. The field team did not have a conservator at that stage, and I was invited to join the excavation as a matter of urgency to care for the deposit (or cache) containing the figures and take responsibility for lifting it. Little did I know then, almost 20 years ago, that I was beginning a relationship with the statues that was to be such a challenge and last so long.

Over the next five weeks, our main objective was to remove the cache safely from the site. This involved further archaeological excavation to improve access to the deposit containing the statues, an initial evaluation of their composition and condition, and the planning and execution of the removal of the cache. It very soon became clear, as the depth of the deposit was revealed, that it would have to be lifted

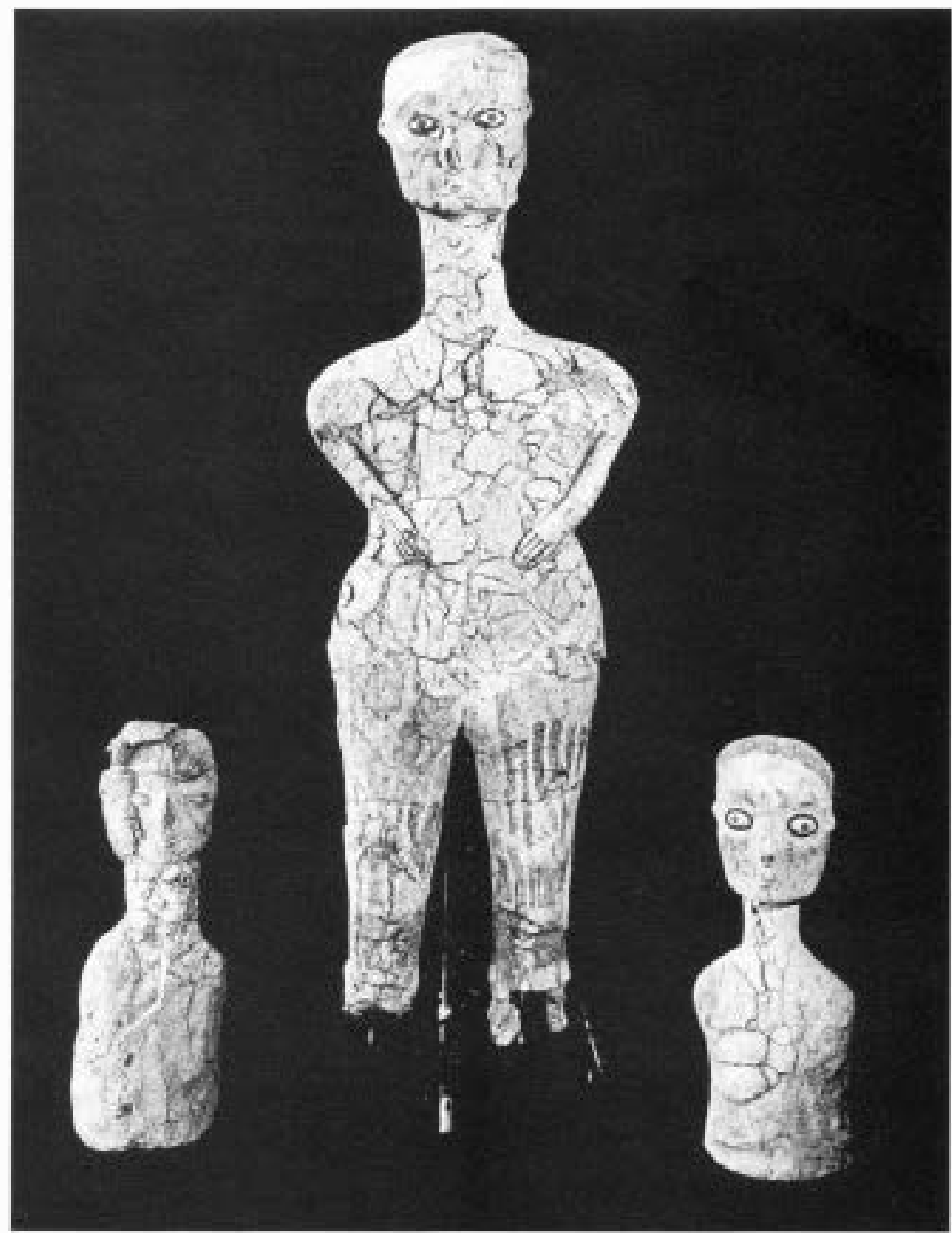

Figure 1 Three of the 'Ain Ghazal statues after conservation; from left to right (known by their informal names) Amos (height $36 \mathrm{~cm})$, Zeina $(93 \mathrm{~cm})$, Uriah $(38.5 \mathrm{~cm})$. 


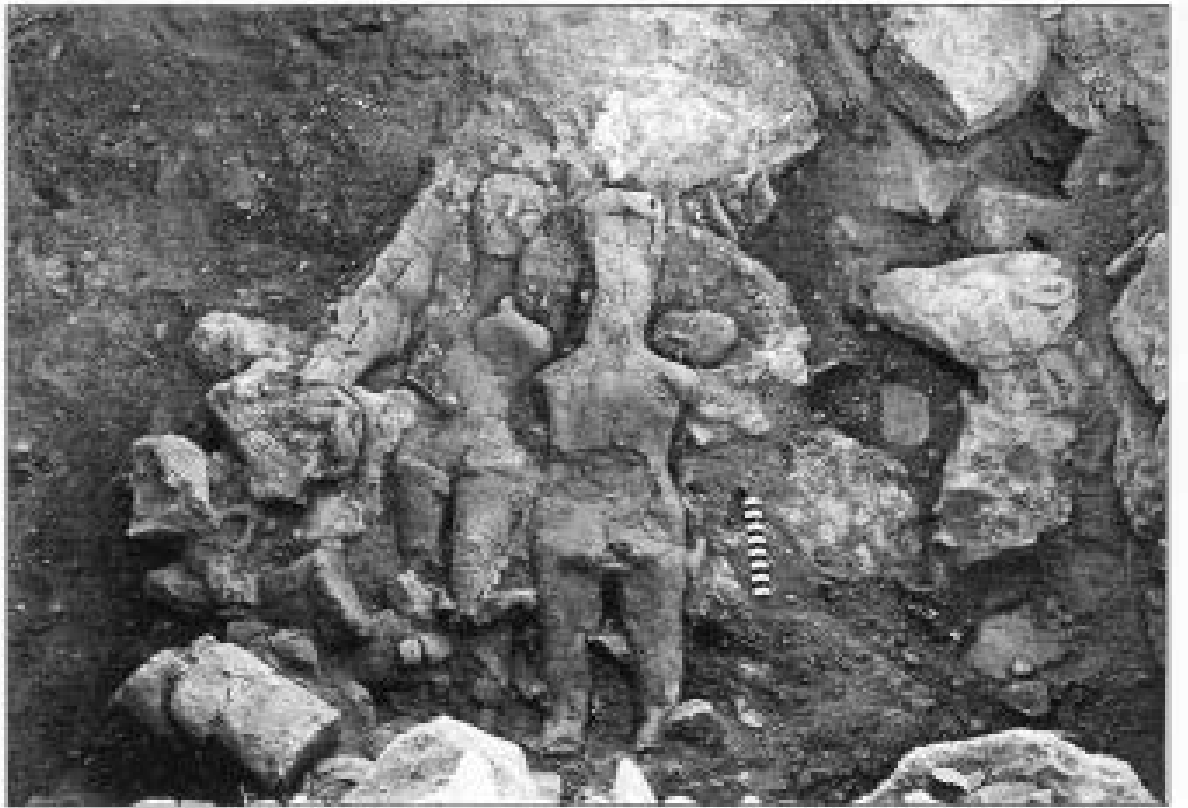

Figure 2 The cache of statues in situ at 'Ain Ghazal during excavation, 1983 (scale bar $15 \mathrm{~cm}$ ).

as a block, so that skilled excavation could proceed later away from the site, at a pace consistent with the needs of the statues. The removal involved intensive team effort and, mercifully, was successful. With the cache installed in a crate, safely lifted, and removed from the site, the first-aid rescue stage of the conservation process had been achieved.

However, the natural tendency to heave a sigh of relief at that stage and move on to other, more pressing tasks, had to be resisted. Excavation usually results in abrupt environmental changes that are potentially threatening to objects that have

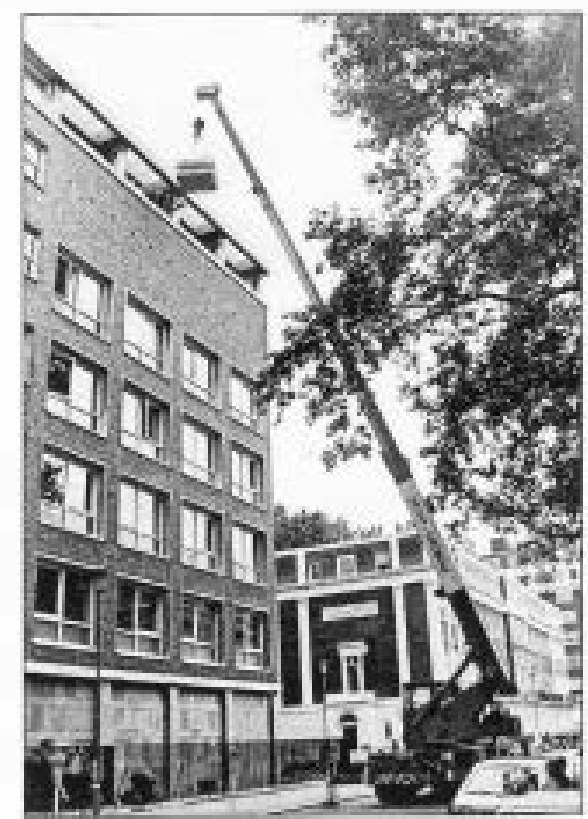

Figure 3 The crate containing the cache of statues suspended from the telescopic crane used to lift it up to the sixth floor of the Institute of Archaeology, London. reached equilibrium within their burial context, and their responses to these changes can seriously damage them. It is therefore essential that the momentum driving the rescue of such a major find is not dissipated through a misguided sense of reduced urgency at this stage in the process of conservation. So, a month after its removal from the site, the crate containing the cache was transferred to the Institute of Archaeology in London. Its size necessitated the use of a telescopic crane to lift it up the outside of the building to the sixth floor (Fig. 3), swing it in over the balcony and ensconce it in one of the conservation laboratories so that treatment and analytical examination of the statues could begin.

\section{The cache and its contents}

How then were these remarkable statues, on which so much effort had been expended, made? We now know, after much difficult and laborious work in the laboratory, that they were made from lime plaster modelled on an internal core or armature of reed bundles lashed together and reinforced with twine (Fig. 4). The statues vary individually, and some of them show traces of having been decorated with pigments such as red and tawny ochres and white clay. The eyes were delineated with a substance made of bitumen and charcoal, a material also used to fashion circular irises, pupils or both, that vary in diameter from statue to statue. The eyeliner was pressed into narrow channels, which it overlapped, surrounding the eyeball (Fig. 5), and was often dusted on the lower lids with emerald-green crystals of dioptase (a hydrated copper silicate that loses its colour if ground too finely). The statues can be divided into two broad categories: full-length figures mostly about 90 $\mathrm{cm}$ in height and with legs and arms, and truncated figures without legs and arms, referred to as busts or dumpies, which are approximately a third of the size of the full-length ones.

Investigation of the cache has shown that the statues were deliberately buried together at the same time in a carefully dug pit levelled off at the bottom. The large figures were laid out in tiers, with the smaller statues arranged in an arc at the base of the feet of the upper tier. Because of their broad bases, the latter were stacked so that heads and bases interleaved to form stable piles. There was no evidence of the uppermost surface having been eroded, so the figures had not been left uncovered, and there is no silting evident between the tiers. Rather, the statues were placed in the pit in intimate contact with one another. They have since become cemented together, possibly by the cycling and recycling of the carbonate to bicarbonate and

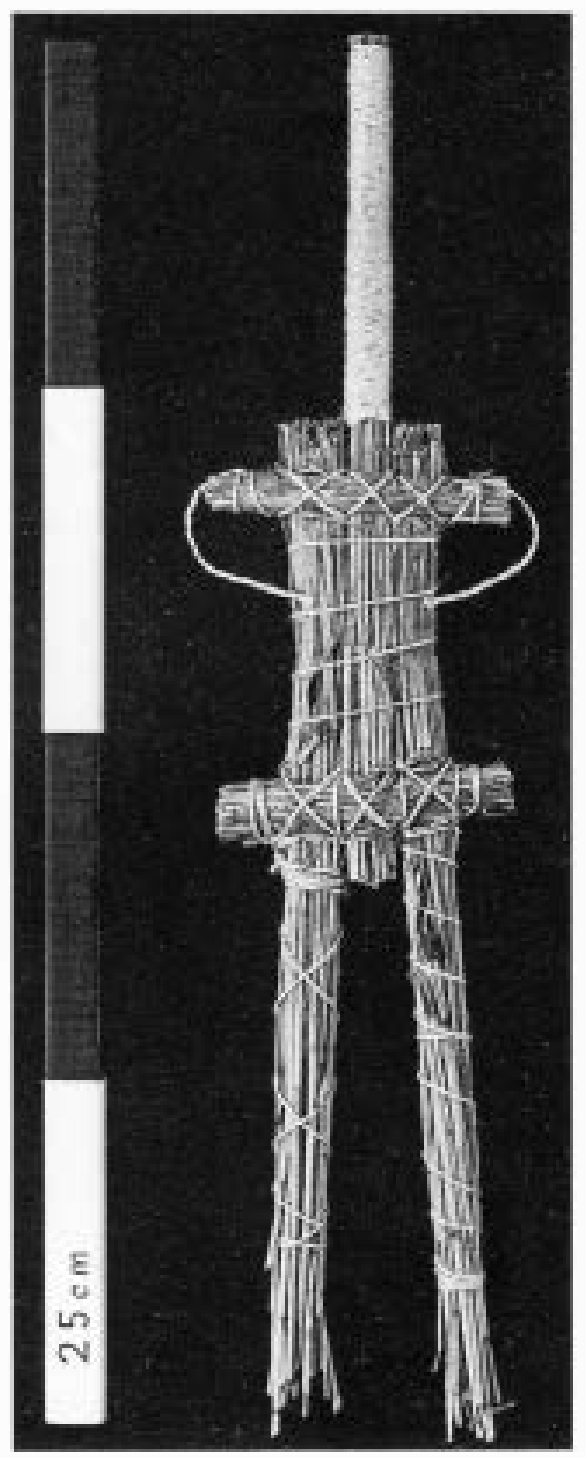

Figure 4 Modern reconstruction of an organic reed and twine core based on impressions left in the interiors of two of the large statues, Reema and Zeina. 


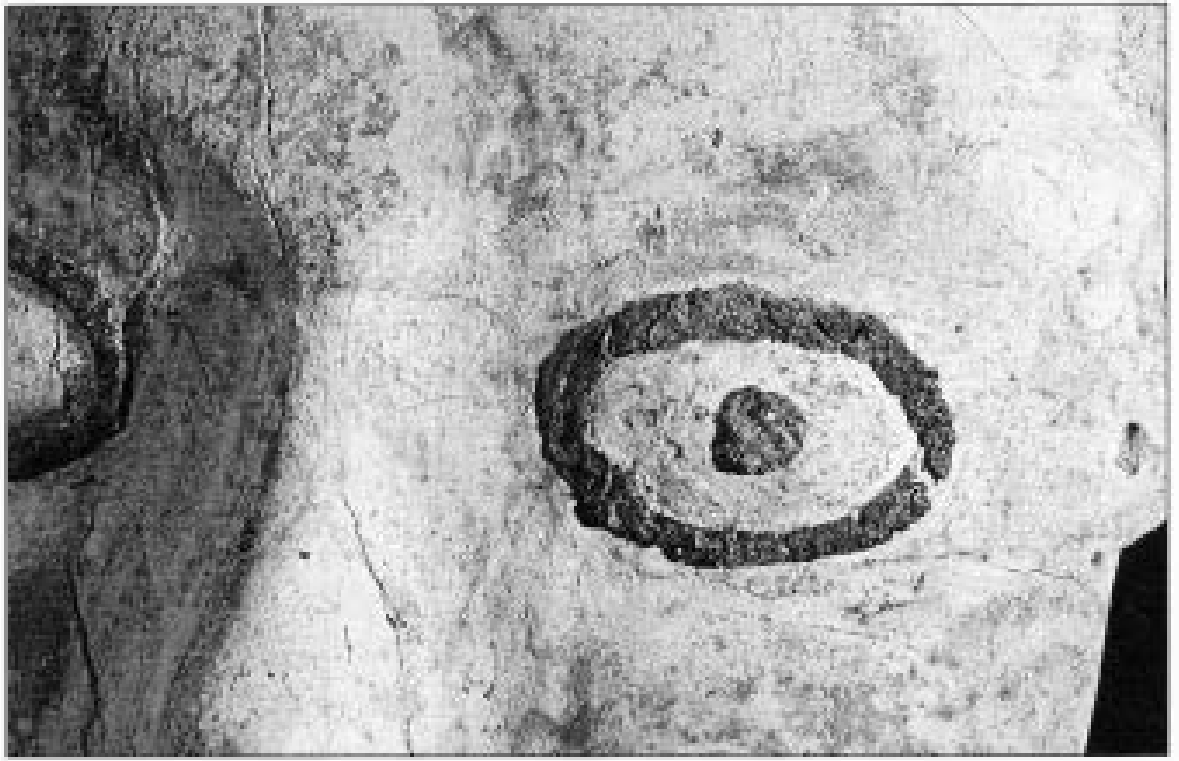

Figure 5 Detail of the left eye of Uriah, showing the eyeball and pupil delineated with a substance made of bitumen and charcoal (the entire head is shown on the front cover of this issue of $\mathrm{AI}$ ).

back again. However, they had all sustained some degree of pre-depositional damage. The fronts of feet are usually missing, although some are incorporated in the cache as disassociated and displaced fragments. The bituminous additions to the eyes are often missing, at least in part. But the haphazardness of the damage does not suggest that it was the result of some ritual form of destruction.

The evident care taken in the disposal of the figures, coupled in particular with the partial absence of the fronts of feet, suggests that they were made not to be buried but to serve some purpose prior to burial. The fact that they were deposited so carefully, and in such a particular arrangement, implies that they may have been cult figures or had a numinous meaning that inspired awe. Perhaps the large number of figures and the individuality of each represent an added dimension of the ancestor worship that is thought to have been practised during the PPNB by various communities in the Levant, including 'Ain Ghazal, evidence for which comes from the removal and decoration of the skulls of some individuals.

\section{Conservation and reconstruction of the statues}

It is extraordinary that the statues survived, having been buried for nearly 9000 years. The organic cores had all but disappeared. The previous existence of the reed bundles was detectable only from occasional silicified particles (known as phytoliths) of their outer tissues and from impressions preserved in the plaster in the interiors of the statues. Because there were voids in the centres of the figures where the reed bundles had been, the weight of the overlying soil had begun to create fractures in the plaster, a process greatly there is sufficient evidence to show that the PPNB occupants of 'Ain Ghazal had a highly developed lime-plaster technology, a discovery that is in itself startling. To our way of thinking, making pottery (which came later) seems much simpler and more straightforward than the burning, slaking and recarbonation of calcareous rock that is involved in the making of lime plaster.

Before we could safely attempt to separate and lift any of the statues prior to surface cleaning, reassembling and reconstructing them, they were thoroughly documented photographically, and we used photogrammetry to preserve information on their relative positions in the cache. Separation and lifting required prior consolidation to strengthen the pieces in preparation for the stresses of moving them. Because of the cracking and breakage already described, lifting an individual statue (Fig. 6) is rather like lifting a skeleton. It may be articulated and intelligible before it is disturbed, but that coherence is lost when it is lifted. Unfortunately the analogy loses its applicability at this point, because the shapes of bones are not arbitrary, whereas the shapes of the fractured fragments of plaster are. Cleaning of the delicate surfaces, including the friable pigment employed as decoration, has proceeded millimetre by millimetre under magnification, using scalpels, tungsten needles mounted in pin vices, dental tools, wooden probes and a variety of soft brushes. Experiments with laser cleaning to try to remove resistant dirt are proving promising.

Reassembly of the plaster fragments to reconstruct a figure constitutes an extremely taxing jigsaw puzzle of enormous complexity, complicated by both lateral and transverse breakage and distortion. Whenever possible, without causing further damage to the statue, the distortion is reversed. This is done by resetting displaced pieces into their original positions,

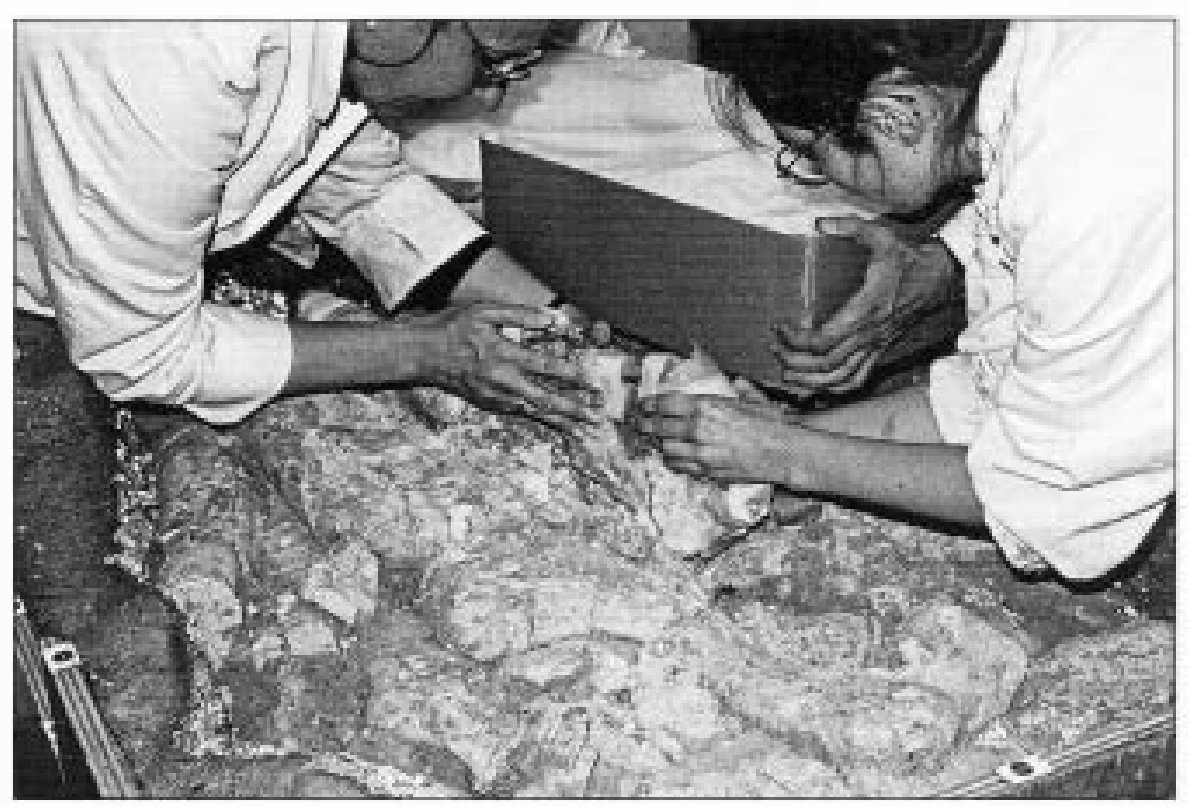

Figure 6 Lifting the torso of one of the large statues in the laboratory. 


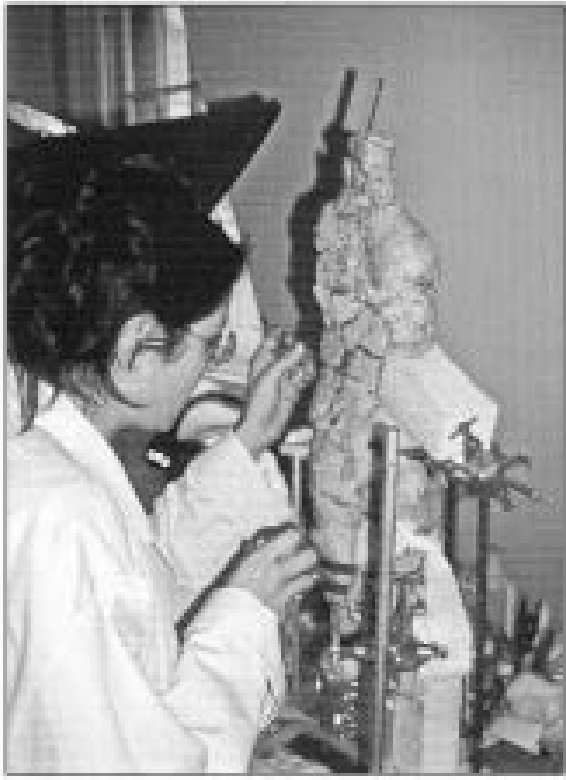

Figure 7 Gap-filling missing areas in the torso of Noah during reassembly and reconstruction on Perspex rods.

so that recreation of the armature (made of Perspex rods shaped to conform loosely to the hollow left by the reed bundle) and reassembly of the pieces can proceed in tandem. The rods are then packed securely into the hollow using cotton wool to prevent them from being able to rattle against the fragile internal plaster surfaces. Missing areas are gap filled using modern materials (Fig. 7), and the fills painted so that they do not appear too obtrusive. Individual mounts are also made to ensure that each figure can be safely studied or exhibited.

The work of conservation and reconstruction continues, ${ }^{4}$ but it is necessarily a slow and labour-intensive enterprise, always subject to interruptions caused by lack of resources. Such an interruption is being experienced now, although efforts are being made to enable full-time work on the statues to be resumed as soon as possible.

At the outset of my involvement with this extraordinary discovery, I never imagined that it would become my life's work, that the statues would become for me what I refer to as "my Jordanian family", or that I would fuss over them and worry about them as if I were a mother hen. It has been an extraordinary privilege to be entrusted with their care and conservation, and I cannot express adequately in words my gratitude to the authorities in Jordan for their trust in me and their unfailing support over these many years. ${ }^{\bar{D}}$

\section{Notes}

1. Very small pieces of charcoal that were found sandwiched between the tightly packed statues were radiocarbon dated at the Oxford Laboratory for Archaeology and the History of Art using the AMS (accelerator mass spectrometric) technique, which allows extremely small samples to be directly dated. The resultant dates were $8700 \pm 80$ and $8660 \pm 80 \mathrm{bp}$; see p. 228 in R. E. M. Hedges, R. A. Housley, I. A. Law, C. R. Bronk, "Radiocarbon dates from the Oxford AMS system: Archaeometry datelist 9", Archaeometry 31, 207234,1989 . The statues were for many years known as the earliest large-scale representations of the human form, until excavations at Nevali Çori in eastern Turkey by the German archaeologist Harald Hauptmann in 1989 and 1990 recovered sculptural antecedents of them carved out of limestone and dating to the early PPNB period (c. 9600 to $c .9200$ years ago).

2. The excavations at 'Ain Ghazal were directed by Gary Rollefson, then at Yarmouk University, Irbid, Jordan, now a visiting professor at Whitman College (Walla Walla, Washington state), with Zeidan Kafafi (Yarmouk University) and Alan Simmons (now of the University of Nevada, Las Vegas), as associate directors.

3. See G. O. Rollefson, "The 1983 season at the Early Neolithic site of 'Ain Ghazal, National Geographic Research 1, 44-62, 1985.

4. Examples of statues that have so far been completely restored can be seen at the Jordan Archaeological Museum (Amman); the Museum of Jordanian Heritage, Institute of Archaeology and Anthropology, Yarmouk University (Irbid, Jordan); and the British Museum. For further information on the recovery and conservation of the statues, see K. W. Tubb, "Preliminary report on the 'Ain Ghazal statues", Mitteilungen der Deutschen Orient Gesellschaft zu Berlin 117, 117-34, 1985; K. W. Tubb, "Conservation of the lime plaster statues of 'Ain Ghazal", in Recent advances in the conservation and analysis of artifacts, J. Black (ed.), 387-91 (London: Summer School Press); and K. W. Tubb \& C. A. Grissom, "'Ayn Ghazal: a comparative study of the 1983 and 1985 statuary caches", in Studies in the history and archaeology ofJordan, vol. v, 437-47 (Amman: Department of Antiquities, 1995).

5. Work on the statues has always been collaborative and has involved many different individuals whose contributions have been vital to its success. I am deeply indebted to them all. Susanne Ryder, who devoted five years to the care and conservation of the statues, deserves special mention for her loyalty to the material and her perseverance with the project. She has been not only an esteemed colleague but is also a dear friend. 